\title{
Time-dependent effects of exposure to static magnetic field on glucose and lipid metabolism in rat
}

\author{
Aida Lahbib ${ }^{1}$, Myriam Elferchichi ${ }^{1}$, Soumaya Ghodbane ${ }^{1}$, Hatem Belguith ${ }^{2}$, Sihem Chater ${ }^{1}$, \\ Mohsen Sakly ${ }^{1}$ and Hafedh Abdelmelek ${ }^{1}$ \\ ${ }^{1}$ Laboratoire de Physiologie Intégrée, Faculté des Sciences de Bizerte, Jarzouna, Tunisia \\ ${ }^{2}$ Laboratoire de Biochimie, Faculté des Sciences de Bizerte, Jarzouna, Tunisia
}

\begin{abstract}
In the following study, we investigate the effects of static magnetic field (SMF) (128 mT, $1 \mathrm{~h}$ /day during 5 or 15 consecutive days) on anthropometric parameters, glucose and lipid metabolism in rats. Exposure to SMF during 5 days induced a decrease $(-8 \%, p<0.05)$ in relative liver weight and serum insulin concentration $(-56 \%, p<0.001)$, while blood glucose level was increased $(+10 \%, p<$ 0.001). By contrast, the same treatment failed to alter body weight, relative kidney weight and levels of lactate, cholesterol, triglycerides and phospholipids. Exposure to SMF during 15 days induced a decrease $(-15 \%, p<0.001)$ in body weight, liver weight $(-15 \%, p<0.05)$, insulin concentration $(-63 \%, p<0.001)$, plasmatic lactate level $(-55 \%, p<0.05)$ and increased glucose $(+24 \%, p<0.001)$, cholesterol $(+30 \%, p<0.01$, ) and phospholipids levels $(+58 \%, p<0.001)$, whereas, triglycerides decreased $(-28 \%, p<0.001)$. These results showed that SMF effects on glucose and lipid metabolism are time-dependent.
\end{abstract}

Key words: Static magnetic field - Body weight - Metabolism - Rats

\section{Introduction}

Despite the increasing number of studies on static magnetic field (SMF) effects, data reported in literature are quite heterogeneous in terms of SMF intensity and time of exposure.

Biochemical studies have evaluated the effects of electric fields and SMF on the metabolism of cell cultures, animals, and humans (Stuchly et al. 1986; Kowalczuk et al. 1991). SMFs can penetrate in biological tissues freely and can interact directly with moving charges and magnetic materials found in tissues through several physical mechanisms (WHO, 2006).

The exposure of rats to $9.4 \mathrm{~T} \mathrm{SMF}$ for 10 weeks had no effect on spatial memory, food, water consumption, body weight, and biochemical parameters (High et al. 2000). By contrast, the exposure of mice to $5 \mathrm{~T}$ for 48 hours suppresses eating and drinking behaviour and increases the blood urea nitrogen and creatinine concentrations (Tsuji et al. 1996). Chater et al. (2006 a) demonstrated that exposure of pregnant rats during 13 days failed to alter body weight

Correspondence to: Aida Lahbib, Laboratoire de Physiologie Integrée, Faculté des Sciences de Bizerte, 7021 Jarzouna, Tunisia E-mail: aida_lagui@yahoo.fr and triglycerides concentrations. Moreover, exposure to SMF increased blood glucose and decreased insulin release, leading to a diabetic-like state in pregnant rats (Chater et al. 2006a). In addition, High et al. (2000) showed that under SMF (4.9 T, during 10 weeks) body weight and biochemical parameters remained unchanged.

SMF is known to be strongly lipolytic and glycogenolytic in rats, inducing an increase in blood glucagon, cortisol, and thyroxin levels (Gorczynska et al. 1989; Chernysheva et al. 1990). Abdelmelek et al. (2006) demonstrated that SMF exert a controlling influence on sympathetic nervous system activity and Heat Shoc Protein 72 (HSP 72) in rats. Moreover, sub-acute exposure to SMF (128 mT, $1 \mathrm{~h}$ /day during 13 days) enhances apoptosis and stimulates biosynthesis of plasma corticosterone and metallothionein activities in female rats (Chater et al. 2004). In part, the mechanism for this stress response by SMF is believed to be related to oxidative stress (Khadir et al. 1999; Kula et al. 2000; Simko et al. 2001; Chater et al. 2006a; Amara et al. 2007).

The present study attempt to exhibit the time-dependent effect of SMFs (128 mT, $1 \mathrm{~h}$ /day) on metabolism to test whether the time of exposure can disrupt glucose and lipid metabolism in rats. 


\section{Materials and Methods}

\section{Animals}

Adult Wistar male rats (SIPHAT, Tunisia), weighing $100-150 \mathrm{~g}$ were randomly divided into control $(n=6)$ and SMF-exposed rats $(n=6)$. Animals were housed in group of six in cages at $25^{\circ} \mathrm{C}$ with the relative humidity of $80 \%$, under a $12: 12 \mathrm{~h}$ light/dark cycle, with free access to water and commercial wash (Company Almes, Mateur, Tunisia). Animals were cared for, under the Tunisian code of practice for the Care and Use of Animals for Scientific Purposes. The experimental protocols were approved by the Faculty Ethics Committee (Faculté des Sciences de Bizerte, Tunisia).

\section{Exposure System}

We used Lake Shore electromagnets (EM4-HV, Magnet Power supply Model 647, Lake Shore Cryotronic, Westerville, USA) with an air gap of $15 \mathrm{~cm}$. This apparatus incorporates water cools coils and precision yokes that assure precise cap alignment and excellent field stability and uniformity when high power is required to achieve the maximum field capability for the electromagnet. SMF intensity was measured and standardized over the total floor area of the Plexiglas cage at $128 \mathrm{mT}$. The cage is $20 \mathrm{~cm}$ long, $10 \mathrm{~cm}$ wide and $20 \mathrm{~cm}$ high. The two bobbins of the Lake Shore System were separated by $12 \mathrm{~cm}$ gap.

\section{Treatment}

Male rats were exposed to the SMF for $1 \mathrm{~h}$ /day (between 9-12 h) during 5 and 15 consecutive days. The cage in the Lake Shore System contained two rats for each exposure. The control rats were placed in the same conditions without applying the SMF.

\section{Procedure}

Exposed and sham group were sacrificed. Blood samples were immediately collected in heparinized chilled tubes and centrifuged. Aliquots of plasma were frozen and stored at $-80^{\circ} \mathrm{C}$ until use.

\section{Body, liver and kidney weight}

Each rat was weighed with a triple beam balance with 0.1gram readability on a daily basis between 9 and 10 a.m. During the weight measurement the cages were cleaned, the straw renewed, and sufficient amounts of water and rat food were replenished every day. Animals were sacrificed and the liver and kidney were immediately removed and weighed, then the organs weight ratio was calculated. The relative weight was calculated as $\mathrm{g} / 100 \mathrm{~g}$ body weight.

\section{Blood tests}

Plasma glucose and triglyceride levels were determined from standard curves generated at the same time using enzymatic methods and following the manufacturer's instructions (Sigma 510, and serum Triglycerides Determination Kit TR0100, Sigma, France). The blood glucose level was measured by a glucometer (Accu-Chek active Roche, Schwitzerland). The colorimetric enzymatic test CHOD-PAP (Biomaghreb, Tunisia) was used for cholesterol quantification using internal standard according to the manufacturer's instructions. Insulin concentration was determined from a standard curve generated using an ELISA assay (Mercodia Ultrasensitive Insulin ELISA, USA). The colorimetric enzymatic test (Laclacl Lactate Plasma LCR Kit, Roche) was used for lactate quantification using enzymatic methods and following the manufacturer's instructions and plasmatic phospholipids were analysed following the method developed by Shibuya et al. (1967) using a standard curve.

\section{Data presentation and statistical analysis}

Data are reported as the mean \pm SEM. Differences between means were evaluated by one-way analysis of variance (ANOVA). Statistical significance of the differences between means was assessed by Student's $t$-test.

\section{Results}

SMF exposure (128 mT, $1 \mathrm{~h}$ /day) during 5 consecutive days failed to alter rat body weights $(140.45 \pm 3.83 v s .143 .03 \pm 4.65$, $p>0.05$ ) (Fig. 1), while treatment during 15 days decreased body weight $(206.30 \pm 8.40$ vs. $244.40 \pm 21.40, p<0.001)$

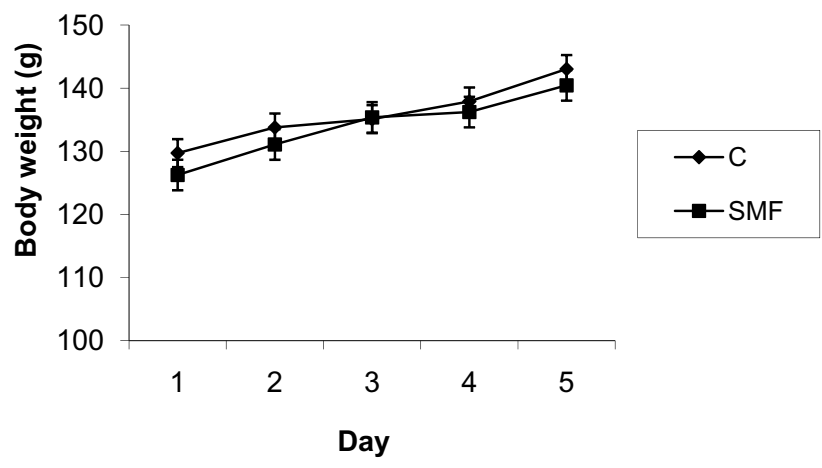

Figure 1. Effect of exposure to SMF ( $128 \mathrm{mT}, 1 \mathrm{~h} / \mathrm{d}$ ) for 5 days on body weight. Values are means \pm SEM of six determinations. $p>0.05$ compared to control (ANOVA). C, control; SMF, static magnetic field. 
Table 1. Effect of 15 days-lasting exposure to static magnetic field (128 mT, $1 \mathrm{~h} / \mathrm{d}$ ) on body weight

\begin{tabular}{|c|c|c|}
\hline \multirow{2}{*}{ Day } & \multicolumn{2}{|c|}{ Body weight (g) } \\
\hline & $\mathrm{C}$ & SMF \\
\hline 0 & $211.60 \pm 16.70$ & $199.80 \pm 7.90$ \\
\hline 15 & $244.40 \pm 21.40$ & $206.30 \pm 8.40^{\star \star * *}$ \\
\hline $\mathrm{d} 15-\mathrm{d} 0$ & $32.80 \pm 13.30$ & $6.50 \pm 2.60^{\star * *}$ \\
\hline
\end{tabular}

Values are means \pm SEM of six determinations. ${ }^{* *} p<0.001 \mathrm{com}-$ pared to control (ANOVA). C, control; SMF, static magnetic field.

(Table 1). Relative liver weight decreased in SMF exposed rats during $5(4.06 \pm 0.06 v s .4 .39 \pm 0.10, p<0.05)$ or 15 days $(3.02 \pm 0.05 v s .3 .47 \pm 0.15, p<0.05)$ (Fig. 2). In contrast, relative kidney weight remained unchanged (Fig. 3).

SMF-exposed rats presented higher glycaemia than sham control animals after 5 days $(101.40 \pm 2.22 v s .91 .80 \pm 2.16 \mathrm{mg} /$ $\mathrm{dl}, p<0.001)$, or 15 days (205.60 \pm 5.90 vs. $166.00 \pm 4.20 \mathrm{mg} /$ $\mathrm{dl}, p<0.001$ ) (Fig. 5). The increase of glycaemia is associated with a lower insulinemia in 5 days $(0.93 \pm 0.09$ vs. $2.12 \pm 0.34$, $p<0.001)$ or 15 days $(1.73 \pm 0.48 v s .4 .68 \pm 0.15 \mathrm{ng} / \mathrm{dl}, p<$ 0. 001) treated rats (Fig. 4). In SMF exposure rats during 15 days, we observed an enhancement in lactate $(3.20 \pm 0.45 \mathrm{vs}$. $1.45 \pm 0.14 \mathrm{mM}, p<0.001$ ) (Fig. 6), cholesterol (1.26 \pm 0.06 vs. $0.97 \pm 0.04 \mathrm{~g} / \mathrm{l}, p<0.01)$, phospholipids levels $(1.64 \pm 0.14$ vs. $1.04 \pm 0.04 \mathrm{mg} / \mathrm{ml}, p<0.001$ ) (Table 2) and a decrease in triglycerides $(47.40 \pm 8.69 v s .66 .06 \pm 11.00 \mathrm{mg} / \mathrm{dl}, p<0.001)$. Exposed group during 5 days failed to alter plasmatic lactate level and these metabolic parameters.

\section{Discussion}

In the present study, we showed that duration of exposure to SMF produced alteration in body weight and metabolic parameters in rat. We found that exposure to SMF during

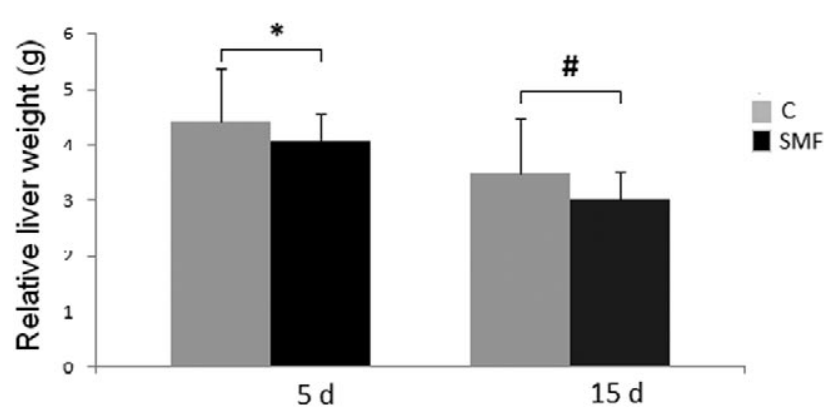

Figure 2. Relative liver weight decrease during the exposure to static magnetic field (SMF $128 \mathrm{mT}, 1 \mathrm{~h} / \mathrm{d}$ ). Values are means \pm SEM of six determinations. ${ }^{* * *} p<0.05,{ }^{*} p<0.005$ compared to control (ANOVA). C, control; $5 \mathrm{~d}$, static magnetic field during 5 days; $15 \mathrm{~d}$, static magnetic field during 15 days.
5 days (128 mT, $1 \mathrm{~h} /$ day) did not affect rat body weight as previously reported by Chater et al. (2006) (128 mT, 1 h/day during 13 days). In accordance with previous data (Wilson et al. 1999; WHO 2006), the prolongations of exposure for 15 days affect body weight $(-15 \%)$. This effect could be explained by changes in eating habits or metabolic changes (Sandrey et al. 1999, 2002). The decrease of body weight might be also due to the decrease in body fluid and protein content or other factors including hormonal changes (Hashish et al. 2008). Besides, the present investigation showed that exposure to SMF for 5 or 15 days produced relative liver weight loss. This result can be explained by a possible stimulation of glycogenolyse by hypersympathetic activity induced by SMF in rats (Abdelmelek et al. 2006).

Because the SMF effects on body weight and relative liver weight and possible stimulation in glycogenolyse and hormo-

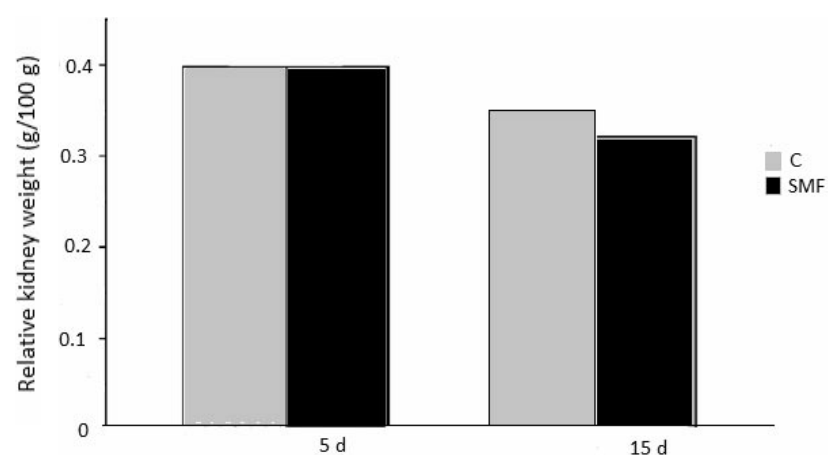

Figure 3. Relative kidney weight after exposure to static magnetic field (SMF $128 \mathrm{mT}, 1 \mathrm{~h} / \mathrm{d}$ ). Values are means \pm SEM of six determinations. $\mathrm{C}$, control; $5 \mathrm{~d}$, static magnetic field during 5 days; $15 \mathrm{~d}$, static magnetic field during 15 days.

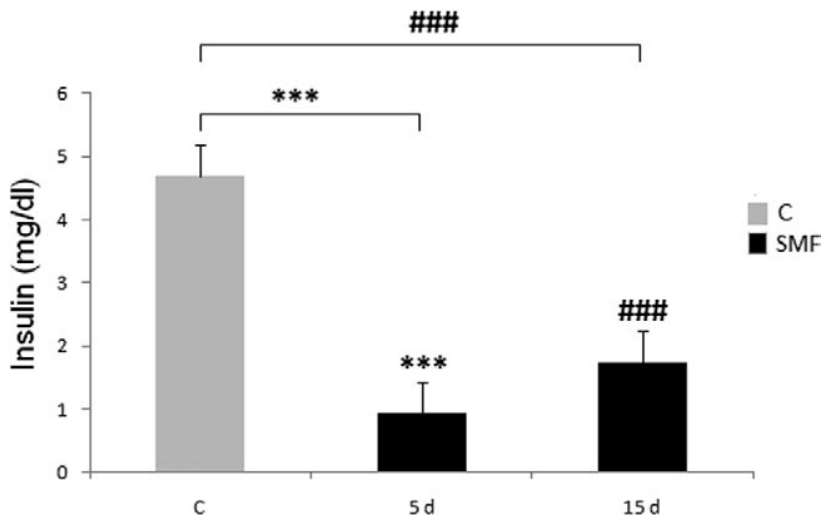

Figure 4. Effect of exposure to static magnetic field (SMF $128 \mathrm{mT}$, $1 \mathrm{~h} / \mathrm{d}$ ) on insulin concentration. Values are means \pm SEM of six determinations. ${ }^{* *} p<0.001$, ${ }^{\# \#} p<0.001$ compared to control (ANOVA). C, control; $5 \mathrm{~d}$, static magnetic field during 5 days; $15 \mathrm{~d}$, static magnetic field exposure during 15 days. 
Table 2. Effect of exposure to static magnetic field on lipid parameters

\begin{tabular}{lccc}
\hline \multirow{2}{*}{ Parameters } & \multirow{2}{*}{$\mathrm{C}$} & \multicolumn{2}{c}{ SMF } \\
\cline { 3 - 4 } & & 5 days & 15 days \\
\hline Triglycerides $(\mathrm{mg} / \mathrm{dl})$ & $66.06 \pm 11.00$ & $58.00 \pm 10.40$ & $47.40 \pm 8.69^{* * *}$ \\
Cholesterol $(\mathrm{g} / \mathrm{l})$ & $0.97 \pm 0.04$ & $0.67 \pm 0.04$ & $1.26 \pm 0.06^{* *}$ \\
$\begin{array}{l}\text { Phospholipids } \\
(\mathrm{mg} / \mathrm{ml})\end{array}$ & $1.04 \pm 0.04$ & $0.63 \pm 0.13$ & $1.64 \pm 0.14^{* * *}$ \\
\hline
\end{tabular}

Values are means \pm SEM of six determinations. ${ }^{* *} p<0.01$, ${ }^{* *} p<$ 0.001 compared to control (ANOVA). C, control; SMF, static magnetic field.

nal changes, we tried to investigate the glucose metabolism following SMF exposition.

Our data demonstrated that SMF exposition $(128 \mathrm{mT}$, 1 hour) during 5 or 15 consecutive days elevated blood glucose level and the effect is time-dependent. Hyperglycaemia may be attributed to the release of the hyperglycaemic hormone (glucagon) and/or the inhibition of the hypoglycaemic hormone (insulin) as previously shown by Gorczynska (1989). Our findings are supported by the report of Chater et al. (2006a,b), St. Pierre et al. (2008) and Tsuji et al. (1996). Other findings showed that blood glucose level was not affected (Sutter et al. 1987; Harakawa et al. 2005; Mehrshad et al. 2007), or decreased (Gorczynska et al. 1989; Laitl-Kobierska et al. 2002; Sakurai et al. 2005) after SMF exposition. We can hypothesize this difference in results by the different strength and/or the duration of exposition to the magnetic field.

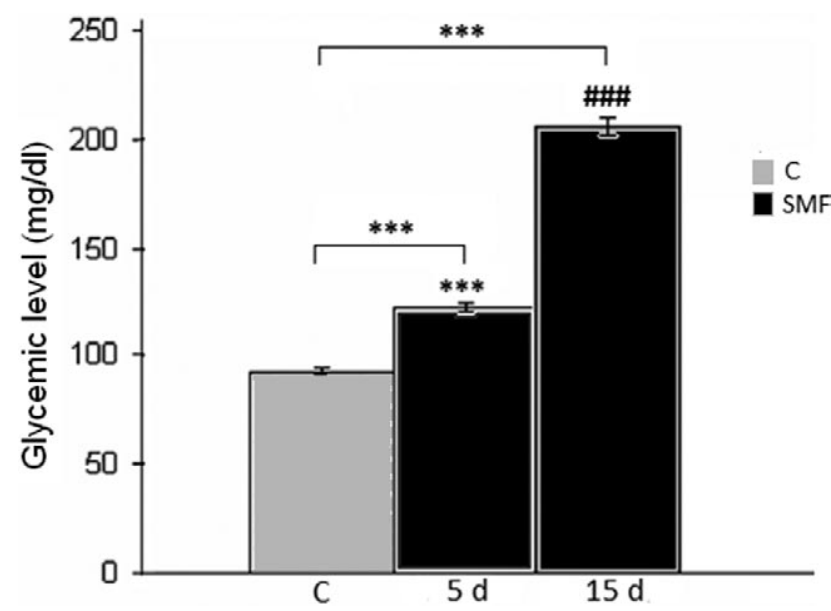

Figure 5. Glucose content in blood of rats during exposure to static magnetic field $(128 \mathrm{mT}, 1 \mathrm{~h} / \mathrm{d})$. Values are means \pm SEM of six determinations. ${ }^{* * *} p<0.001,{ }^{\# \# \#} p<0.001$ compared to control (ANOVA). C, control; $5 \mathrm{~d}$, static magnetic field exposure during 5 days; $15 \mathrm{~d}$, static magnetic field exposure during 15 days.
In rats exposed during 5 days, the increase in glucose plasma was accompanied with a normal serum lactate level. Normal lactate level in this group can be owed to the fact that lactate production in muscle was exchanged between diverse cells and tissues, including astrocytes and neurons (Amara et al. 2007). Nonetheless, under SMF, rats exposed during 15 days displayed an increase in lactate concentration. This increase of lactate can be the sign of hypoxia state, as suggested by several authors (Bicego et al. 2002; Steiner et al. 2002; Gargaglioni et al. 2003).

The alteration in glucose metabolism is associated to a great decrease in plasmatic insulin concentration observed in both groups. This result is supported by previous data (Hayek et al. 1984; Sakurai et al. 2005; Chater et al. 2006a). Miyakoshi et al. (2006) using a system for exposure of cultured cell (ELF $60 \mathrm{~Hz}, 5 \mathrm{mT}, 1 \mathrm{~h}$ ), showed also a significant decrease in insulin release. The low level of insulin may be result from sympathetic hyperactivity induced by SMF (Abdelmelek et al. 2006).

Under SMF, and following 5 days of exposure, triglycerides, cholesterol and phospholipids levels remain unchanged. The fact that serum triglycerides concentrations were not affected by SMF exposure suggests that lipid metabolism is insensitive to SMF acute exposure (Chater et al. 2006b). Our result is in disagreement with data reported by Bellossi et al. (1996) showing that SMF exposure $(6 \mathrm{mT}, 24 \mathrm{~h})$ induced a decrease in plasma cholesterol and triglycerides concentrations. However, plasma cholesterol and phospholipids contents increased, whereas triglycerides decreased when the treatment was prolonged for 15 days. An excess of circulating lipids is often associated with glucose metabolism deregulation (Boden and Shulman 2002; Savage et al. 2007).

Finally, increase in cholesterol and phospholipids levels may be related in part to alteration in membrane integrity (Grynberg et al. 2007) caused by SMF exposition.

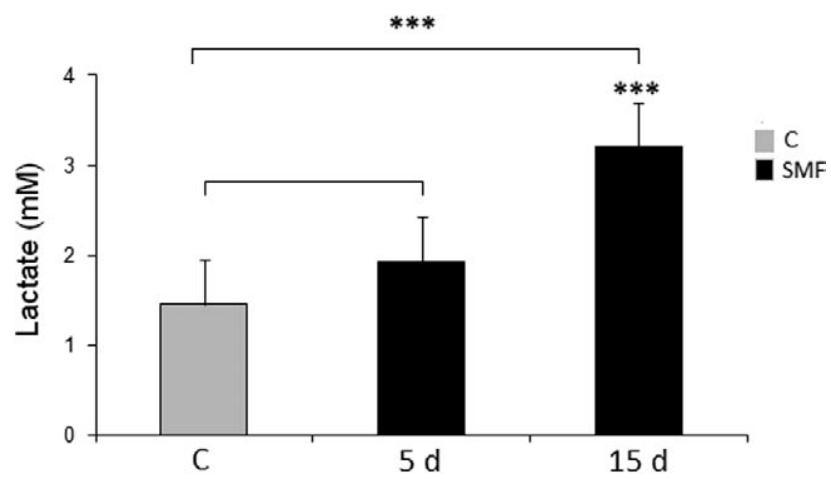

Figure 6. Effect of $128 \mathrm{mT}$ static magnetic field on lactate concentrations. ${ }^{* *} p<0.01$ compared to control (ANOVA). C, control; $5 \mathrm{~d}$, static magnetic field during 5 days; $15 \mathrm{~d}$, static magnetic field during 15 days. 


\section{Conclusion}

In conclusion, we demonstrated that the effects of SMF are closely dependent on the duration of exposure. The short-time exposition to SMF induces alteration in glucose metabolism, but long-time exposition alters both glucose metabolism and lipid metabolism.

\section{References}

Abbasi M., Nakhjavani M., Hamidi S., Tarafdari A. M., Esteghamati A. (2007): Constant magnetic field of $50 \mathrm{mT}$ does not affect weight gain and blood glucose level in BALB/c mice. Med. Sci. Monit. 13, BR151-154

Abdelmelek H., Molnar A., Servais S., Cottet-Emard J. M., Pequignot J. M., Favier R., Sakly M. (2006): Skeletal muscle HSP72 and norepinephrine response to static magnetic field in rat. J. Neural. Transm. 113, 821-827; doi:10.1007/s00702-005-0364-7

Amara S., Abdelmelek H., Garrel C., Guiraud P., Douki T., Ravanat J. L., Favier A., Sakly M., Ben Rhouma K. (2007): Zinc supplementation ameliorates static magnetic field-induced oxidative stress in rat tissues. Environ. Toxicol. Pharmacol. 23, 193-197; doi:10.1016/j.etap.2006.09.001

Bellossi A., Pouvreau-Quillien V., Rocher C., Ruelloux M. (1996): Effect of pulsed magnetic field on cholesterol and triglyceride levels in rat study of field intensity and length of exposure. Z. Naturforsch. 51, 603-606

Bicego K. C., Steiner A., Gargaglioni H. L., Branco L. G. (2002): Is lactate a mediator of hypoxia-induced anapyrexia? Pflugers. Arch. 444, 810-815; doi:10.1007/s00424-0020886-X

Boden G., Shulman G. I. (2002): Free fatty acids in obesity and type 2 diabetes. Defining their role in the development of insulin resistance and beta-cell dysfunction. Eur. J. Clin. Invest. 32, Suppl. 3, 14-23; doi:10.1046/j.13652362.32.s3.3.x

Chater S., Abdelmelek H., Sakly M., Ben Rhouma K. (2004): Effects of subacute exposure to magnetic field on synthesis of plasma corticosterone and liver metallothionein levels in female rats. Pak. J. Med. Sci. 20, 219-223

Chater S., Abdelmelek H., Pequignot J. M., Sakly M., Ben Rhouma K. (2006a): Effects of sub-acute exposure to a static magnetic field on hematologic and biochemical parameters in pregnant rats. Electromagn. Biol. Med. 25, 1-10; doi:10.1080/15368370600860135

Chater S., Abdelmelek H., Couton D., Joulin V., Sakly M., Ben Rhouma K. (2006b): Subacute exposure to magnetic field induced apoptosis in thymus female rats. Pak. J. Med. Sci. 21, 292-297

Chernysheva O. N. (1990): Status of the lipid phase of plasma membranes of the heart after repeated exposure to alternate magnetic of $50 \mathrm{~Hz}$ frequency. Kosm. Biol. Aviakosm. Med. 24, 30-31 (in Russian)

Gargaglioni H. L., Bicego Kenia C., Steiner A., Branco L. G. (2003): Lactate as a modulator of hypoxia-induced hyperventila- tion. Respir. Physiol. Neurobiol. 138, 37-44; doi:10.1016/ S1569-9048(03)00172-1

Gorczynska E., Wegrzynowics R. (1989): Effect of static magnetic field on some enzymes activities in rats. J. Hyg. Epi. Micro. Immun. 33, 149-155

Grynberg A. (2007) : Acides gras poly-insaturés, phospholipides et fonctions membranaires. In: Traité de nutrition artificielle de l'adulte, p. 120

Harakawa S., Inoue N., Hori T., Tochio K., Kariya T., Takahashi K., Doge F., Martin D. E., Saito A., Suzuki H., Nagasawa H. (2005): Effects of exposure to a $50 \mathrm{~Hz}$ electric field on plasma levels of lactate, glucose, free Fatty acids, triglycerides and creatine phosphokinase activity in hind-limb ischemic rats. J. Vet. Med. Sci. 67, 969-974; doi:10.1292/jvms.67.969

Hashish A. H., El-Missiry M. A., Abdelkader H. I, Abou-Saleh R. H. (2008): Assessment of biological changes of continuous whole body exposure to static magnetic field and extremely low frequency electromagnetic fields in mice. Ecotoxicol. Environ. Saf. 71, 895-902; doi:10.1016/j.ecoenv.2007.10.002

Hayek A., Guardia A., Guardian J., Obaraski G. (1984): Homogeneous magnetic field influence pancreatic islet function in vitro. Biochem. Biophys. Res. Commun. 122, 191-196; doi:10.1016/0006-291X(84)90458-3

High W. B., Sikora J., Ugurbil K., Garwood M. (2000): Subchronic in vivo effects of a high static magnetic field $(9.4 \mathrm{~T})$ in rats. J. Mag. Res. Imag. 12, 122-139; doi:10.1002/15222586(200007)12:1<122::AID-JMRI14>3.0.CO;2-C

Khadir R., Morgan J. L., Murray J. J. (1999): Effects of $60 \mathrm{~Hz}$ magnetic field exposure on polymorphonuclear leukocyte activation. Biochem. Biophys. Acta. 1472, 359-367

Kowalczuk C. I., Sienkiewicz Z. J., Saunders R. D. (1991): Biological effects of exposure to non-ionizing electromagnetic fields and radiation. I. Static electric and magnetic fields. National Radiological Protection Board NRPR-R238, Didcot, UK

Kula B., Sobczak A., Kuska R. (2000): Effects of static and ELF magnetic fields on free-radical processes in rat liver and kidney. Electron. Magnetobiol. 19, 99-105

Laitl-Kobierska A., Cieślar G., Sieroń A., Grzybek H. (2002): Influence of alternating extremely low frequency ELF magnetic field on structure and function of pancreas in rats. Bioelectromagnetics 23, 49-58; doi:10.1002/bem.97

Miyakoshi J. (2006): Biological responses to extremely low-frequency electromagnetic fields. Journal of Dermatological Science, Suppl. 2, S23-30

Sakurai T., Koyama S., Komatsubara Y., Jin W., Miyakoshi J. (2005): Decrease in glucose-stimulated insulin secretion following exposure to magnetic fields. Biochem. Biophys. Res. Commun. 24, 28-32; doi:10.1016/j.bbrc.2005.04.091

Sandrey M. A., Fox M. T., Balcavge W. X., Swez J. (1999): The effects of electromagnetic fields on chemically induced tendonitis in rats. J. Athl. Train. Suppl. 34, S23-26

Sandrey M. A., Vesper D. N., Johnson M. T., Nindl G., Swez J. A., Chamberlain J., Balcavage W. X. (2002): Effect of short duration electromagnetic field exposures on rat mass. Bioelectromagnetics 231, 2-6; doi:10.1002/bem.92 
Savage D. B., Petersen K. F., Shulman G. I. (2007): Disordered lipid metabolism and the pathogenesis of insulin resistance. Physiol. Rev. 87, 507-520; doi:10.1152/physrev.00024.2006

Shibuya I., Honda H., Mario B. (1967): Simplified colorimetry without incineration of phosphorus in phosphatides. Agric. Biol. Chem. 31, 111-114

Simko M., Droste S., Kriehuber R., Weiss D. G. (2001): Stimulation of phagocytosis and free radical production in murine macrophages by $50 \mathrm{~Hz}$ electromagnetic field. Eur. J. Cell. Biol. 80, 562-566; doi:10.1078/0171-9335-00187

Steiner A., Branco L. G. (2002): Hypoxia-induced anaperixia: implications and putative mediators. Annu. Rev. Physiol. 64, 263-288; doi:10.1146/annurev.physiol.64.081501.155856

St-Pierre L. S., Mazzuchin A., Persinger M. A. (2008): Altered blood chemistry and hippocampal histomorphology in adult rats following prenatal exposure to physiologically-patterned, weak (50-500 nanoTesla range) magnetic fields. Int. J. Radiat. Biol. 844, 325-335; doi:10.1080/ 09553000801953300
Stuchly M. A. (1986): Human exposure to static and time-varying magneticfields. Health. Phys. 51, 215-225; doi:10.1097/ 00004032-198608000-00006

Sutter B. C., Billaudel B., Sutter-Dub M. T., Bellossi A. (1987): Effects of constant magnetic fields on the B-cells and insulin target cells in the rat. Aviat. Space. Environ. Med. 58, 537-540

Tsuji Y., Nakagawa M., Suzuki Y. (1996): Five-tesla static magnetic fields suppress food and water consumption and weight gain in mice. Ind. Health. 34, 347-357; doi:10.2486/ indhealth.34.347

WHO (2006): Electromagnetic Fields and Public Health: Static electric and magnetic fields, WHO Fact Sheet 299, Geneva

Wilson B. W., Matt K. S., Morris J. E., Sasser L. B., Miller D. L., Anderson L. E. (1999): Effects of $60 \mathrm{~Hz}$ magnetic field exposure on the pineal and hypothalamic-pituitarygonadal axis in the Siberian hamster (Phodopus sungorus). Bioelectromagnetics 20, 224-232; doi:10.1002/(SICI)1521186X(1999)20:4<224::AID-BEM3>3.0.CO;2-A

Received: April 5, 2010

Final version accepted: August 26, 2010 